\title{
The Importance of Relationship Officers in Banks' Service Marketing
}

\author{
Henry Ajagbawa \\ International Business Management, International School of Management, Paris, France
}

\section{Email address:}

hoajagbawa@yahoo.co.uk

\section{To cite this article:}

Henry Ajagbawa. The Importance of Relationship Officers in Banks' Service Marketing. International Journal of Finance and Banking Research. Vol. 4, No. 1, 2018, pp. 1-12. doi: 10.11648/j.ijfbr.20180401.11

Received: January 19, 2018; Accepted: February 1, 2018; Published: March 2, 2018

\begin{abstract}
AI and intelligent machines are fast substituting the human element in production and delivery of goods and services in all sectors of the economy. In banking, the human factor played by relationship officers is challenged as most relationship management functions are being migrated to alternative channels and platforms. Is this the end of relationship officers in the delivery platform mix? This research asked customers in a Nigerian bank, their perceptions concerning the extent of satisfaction they received from the bank's engrained service culture relative to the satisfaction they derived from the individual style and quality of the relationship officers that work for the bank. Using averages and structural equation modelling, this research provided, with reliability and validity, evidence that the customers placed more premium on the relationship officers than the entire bank's platform of systems and processes. The significance of this result is that banks must evaluate critically the pace, mix and timing, of their migration strategy of relationship management roles from relationship officers to alternative channels and platforms.
\end{abstract}

Keywords: Relationship Officers, Relationship Quality, Culture, Alternative Channels and Platforms, Customer Satisfaction

\section{Introduction}

Banks pursue customers' loyalty for existential reasons by navigating through the progressive pathways of service encounter, customers' trust, commitment, loyalty and engagement (Athanasopoulou, 2009; Avery, Fournier \& Wittenbraker, 2014; Crosby, 1990). However, situating customers' loyalty within the firm can be perplexing. Most literature on the subject discuss loyalty within the strict context of customers' loyalty to the brand (Athanasopoulou, 2009; Huang, 2013), acknowledging that strong relationship strength between the customer and the service provider fosters loyalty. Researchers have indicated that customer loyalty may be mediated by relationship officers' role (Ajagbawa, 2016; Palmatier, Dant, Grewal \& Evans, 2006; Wan, Luk, Fam, Wu \& Chow, 2012). The purpose of this paper therefore, is to investigate customers' perceptions concerning the extent of satisfaction they receive from a bank's engrained service culture relative to the satisfaction they derive from the individual style of the relationship officers (RO) that work for the bank.

\section{Literature Review}

Firms employ optimal channel mix to deliver satisfaction and ultimately achieve customers' loyalty (Goffin, 1998; Kittemann, Gottl, Gabriel \& Menrad, 2008). Banking is in a cross road between the traditional "brick and mortar" channel and the alternative channels in reaching the customers. This transition has become more rapid; reflected in the evolving digital channels and platforms, which are fast substituting the traditional "brick and mortar" channel in the interface between banks and customers (Singh, 2014). The central question, therefore, is whether the importance of the human factor, in the delivery matrix, has waned so much that relationship quality, defined by the strength of the bond between the bank/staff and customers, no longer matters.

Technology has made it possible for banks to reach huge number of customers with limited human interface. Banks are thus becoming extremely impersonal in their service engagement processes evident in banks' behaviors such as purchasing CRM (Customer relationship management) tools off the shelf with assumptions about customers' behaviors 
and expectations that may or may not be correct (Dimitriadis \& Steven, 2008; Kearney, 2009). In this world of commoditization, customers' perceived needs are often subjugated and this could potentially be due to the decreasing level of human interface between banks' RO and the customers. This development tends to constrain the benefits of the essential feedback loop that helps ROs translate customers' feedback into re-imaging products and services design and delivery.

In reality, banks' service architecture builds around processes involving, "integrated risk management, core banking transformation, payment and securities, and customer care" amongst others that help produce the service delivery platform (Keen, Kaushik, Bhogal, Agbara, Simmons, DuLaney \& Allison, 2009). The RO simply represent the actual physical or virtual interface, "encounter" with the customers. Thus, whether a bank is low on "bricks" or high on" digital" delivery, the human factor cannot be eliminated. However, a bank's strategies for handling the interface with the customers define the importance attached to relationship management. Alternative channels such as Call Centers have increasingly become, and rightly so, a substitute for relationship management in the high foot fall retail segment of the market. The dilemma faced by banks is striking the right balance between the "channels and platforms" mix in its relationship management.

Anecdotally, leading organizations like British Airways in the aviation industry and MTN in telecoms have used extensive CRM tools to sponge out critical relationships that must be accorded personal handling. In banks, attention to critical retail segment customers must receive similar attention as other critical segments like private banking and wealth management. Relationship management is a critical aspect of the marketing process that helps to create, nurture and develop value for the firm (Crosby, 1990; Lilien \& Grewal, 2012). The thesis of this paper is that relationship officers (RO) are critical in the marketing proposition of the firm and the paper seeks to answer the extent of importance of the RO viewed from the customer's perspective.

\subsection{Bank's Investment in, and Role of Relationship Officers (RO)}

Organizational theory outlines the range of complex and recursive interactions of the dependent and interrelated components, routines and processes towards achievement of organizational goals (Herold \& Fedor, 2008; McAuley, Duberley \& Johnson, 2007). The RBV (Resource Based View of Strategy) holds that leveraging on the intangible assets (People, "know how", culture) help to build unique firm capabilities, which ultimately confers strategic resources to the firm (Wernerfelt, 2013). The thrust of this paper is to situate the relative importance of the RO within the mix of resources available to banks in achieving their objectives. Consequently, the research asked customers if ROs are more important than the bank's service platform. In this sense, the importance of the RO as a strategic resource to the bank was tested in comparison to the processes and routines on which platform the RO functioned to deliver the services to customers.

To maximize customer value, the bank must not only provide the platform of processes, systems and routines but must also actively engage, train, and renew their RO teams. One major role of the $\mathrm{RO}$ in the customer engagement process is to relate with customers to provide firsthand knowledge of customers' needs to the bank. The service platform provides the absolute minimum standard of service required by the customers and the role of the $\mathrm{RO}$ is to produce a "differentiator" by accentuating the service quality that customers receive from the service platform. The RO, thus, have core deliverables including, filtering customers' needs, develop, nurture, and entrench satisfaction, trust, commitment, and engagement of the customers; ingredients that define the quality of relationship between the bank and its customers.

To strengthen relationship quality, RO invest time, energy, and resources in developing, horning and sustaining interpersonal relationships with the customers nesting on mutual disclosure, friendship, and common social identity (Wan, Luk, Fam, Wu \& Chow, 2012). The assurance of a sound relationship quality with the customer feeds brand loyalty (Avery, Fournier \& Wittenbraker, 2014; Crosby, 1990; Huang, 2013). The banks on their part expend huge budgets to head hunt, train, nurture, and engage RO to deliver on income generating assets and liabilities. Further, banks entrust part of their goodwill and brand image into the hands of the RO who make representations to customers on behalf of the bank.

In the light of this agency relationship between the bank and the RO (Hughes \& Mester, 2008), customers' perceptions of the relative strength of either party and the consequences thereof on current and future business outlook arises. The business outlook expressed as good quality assets and income generating activities of the bank are assured in the face of low staff turnover of the well trained RO (intangible asset). This stability is threatened when RO leave to join competitors. This situation poses a dilemma to banks which can only be resolved within the context of the relative strength of banks' platform, systems and processes compared to the absolute efficiency of the RO. Evidence exists that first class RO have been known to fail in competitors' environment because the competitors were unable to replicate the efficient platforms that enabled the superlative performance of the RO in their former environment (Groysberg, Ashish \& Nitin, 2004; Singh, 2014)

\subsection{Relationship Quality (RQ)}

In a relationship, customers often develop personal closeness and bond with the RO, close only to family members (Athanasopoulou, 2009). Interpersonal interactions, information sharing, and common social identify, develop out of the relationship building process that elevates the otherwise business ties between the customers and RO to a level of personal friendship and bond (Wan, et al, 2012). The close relationship culminates into customer loyalty and 
superior returns for the bank. When this strength of RQ develops, there is potential for incremental value to the bank and paradoxically latency for loss of future business for the bank, when the RO departs to join competitors.

The tripod relationship between the customer, $\mathrm{RO}$, and the bank generate relational challenges of situating customers' allegiance. Anecdote suggests that customers owe their fidelity to $\mathrm{RO}$ as their involvement in resolution of service quality breaches usually reduces the pressure piled by disenchanted customers on the bank. This position is supported by research evidence that indicates that relationship quality negatively mediates service quality (Wan, et al, 2012). Service quality relates to the minimum core service provided by the service platform of the bank. When service failure occurs, effective customer engagement mechanisms could cure the failure and potentially strengthen the relationship if $\mathrm{RO}$ engage customers to enable them ventilate their grievances (Avery, Fournier \& Wittenbraker, 2014; Beverland, Chung \& Kates, 2009)

Spain and Groysberg (2016) had suggested that higher staff turnover predicts poor performance in firms. Therefore, Firms are likely to lose market share when RO leave to join competitors because of customers' willingness to tag along their businesses with the departing RO as a sign of fidelity to the RO. It is a frustrating paradox for banks, which requires delicate handling. It is truly challenging when your once valued assets (RO) threaten and imperil the very existence of the business by joining competitors. This paradox can be resolved within the larger understanding of strong RQ as a pathway capturing processes from relationship formation (Collett, 2011), nurturing to maturity (Benamour \& PrimAllaz, 2010), intangible assets management (People) for enhanced relationship productivity (Wernerfelt, 2013). These processes also capture RO developing relationship bonds, friendship and trust, and the banks instituting processes for service recovery and transgression handling (Yagil \& Luria, 2015). This research used a validated scale employed by Wan, et al (2012) to test firstly, customers' perceptions concerning the extent of RQ received from the bank and RO (Hypothesis 1), and secondly, the overall relationship strength between RQ and the satisfaction construct (Hypotheses 2 and 5).

\subsection{Culture}

Culture is a way of life adopted by a people and a high degree of differences in culture exist across regions and countries (Samaha, Beck \& Palmatier, 2014). Culture has the force of influence over perceptions and attitude (Hofstede, 1991; Triandis, 1989). Thus, culture can be considered both as a cause and consequence (Steel \& Taras, 2010) of environmental factors like demographic, economic, social and political. To the extent of culture inducing perceptual differences amongst people, it is natural that culture should help in investigating the evaluation of purchase intentions of customers. This thesis investigates the impact of culture on customers' perceptions of the satisfaction received from RO and the bank within the framework of the Sivadas, Bruvold and Nelson (2008) culture orientations (Hypotheses 3 and 6).

\subsection{Mediational Effects on the Satisfaction Construct}

Culture is causal to perceptual differences (Bobbio \& Sarrical, 2009) and thus culture may influence customers' evaluation of RQ of the bank or RO. This paper therefore, considers the impact of culture on RQ evaluation by customers. The impact of culture on RQ perception by customers is denoted by the mediation process. Mediation described the notional route of RQ passing through the culture variable towards the satisfaction constructs. This denotes the strength that culture exerts on customers' evaluation of RQ towards the bank or RO. Mediation could be total or partial depending on the pre and post mediation parameters (Hair, Black, Barry \& Rolph, 2013). This research will show whether culture has any influence over customers' evaluation of the RQ it is receiving from the bank's services or from the services provided by the RO that works for the bank (Hypotheses 4 and 7).

\section{Conceptual Framework}

This study rooted its conceptual framework on the theory of planned behavior (Ajzen, 2002) as the building blocks for the causation structure of the model. This paper defined two independent variables, RQ and culture. Instruments that enjoyed validity and reliability from the works of Athanasopoulou (2009) and Wan, Luk, Yau, Tse, Sin, Kwong $\&$ Chow (2009) were used to measure these variables. The measured variables feed into latent factors that defined the independent variables for this study. This paper also defined two measured dependent variables, customers' satisfaction of the overall service assessment of the bank $(\lambda)$ and customers' satisfaction of the overall service assessment of the RO ( $\alpha$ ).

The framework thus tested two separate models, $\lambda$ and $\alpha$, each relying on the two independent variables, RQ and culture. The adoption of the conceptual framework relied on the nature of the latent variables of the study, which reflected the measured proxies. Six indicators selected into RQ (Appendix 1) and fourteen into culture (Appendix 2). Reliability and validity tests trimmed down the indicators to a more parsimonious model consisting only of four and two variables for RQ (Appendix 3) and culture (Appendix 4) respectively. The conceptual framework in Figure 1, relying on the theory of planned behavior, provided a path analysis that defined the structural relationships amongst the variables. The two models, $\alpha$ and $\lambda$, enabled a comparison of the relative importance the customers' ascribed to the bank's service platform and to the specific style of the RO that works for the bank. 


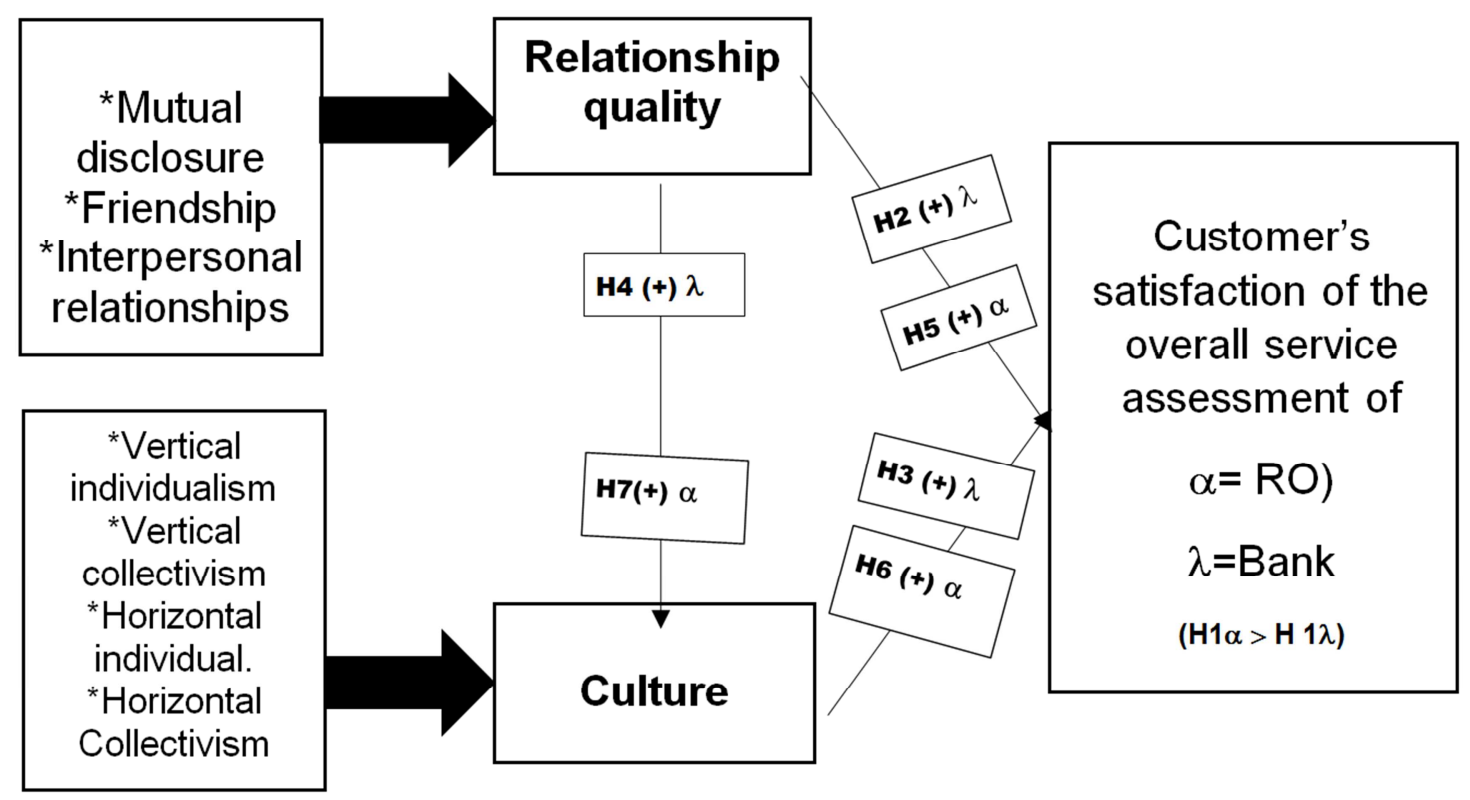

Figure 1. Customers' perceptions of Satisfaction with the bank's and RO' services within the framework of the theory of planned behavior (Capturing the seven hypotheses of the model; $H 1$ to $H 7$ ).

\section{Hypotheses}

Banks perform their intermediation role in an exchange economy by taking deposits and providing loans to customers via the reduction of transactions costs, removal of information asymmetry from the market and entrenchment of specialization (Levine, 2005). Herein lies the importance of $\mathrm{RO}$ as the interface with customers who see RO as the link to these services provided by the banking system. This paper investigated customers' perceptions regarding their satisfaction towards the bank on the one hand and towards the RO on the other hand, within the premises of the defined relationships in the literature review sections, 2., 2.1, 2.2, 2.3 and 2.4. The conceptual framework had linked the concepts from the literature review, captured in sections 2. through to 2.4 above, to establish evidence supporting the seven research hypotheses raised below;

H1: The level of customers' satisfaction of the overall service assessment is higher towards the RO than towards the bank

H2: Relationship quality is positively associated with customers' satisfaction of the overall service assessment of the bank.

H3: Culture is positively associated with customers' satisfaction of the overall service assessment of the bank.

H4: RQ positively mediates the effect of culture on customers' satisfaction of the overall service assessment of the bank.

H5: Relationship quality is positively associated with customers' satisfaction of the overall service assessment of $\mathrm{RO}$

H6: Culture is positively associated with customers' satisfaction of the overall service assessment of RO

H7: RQ positively mediates the effect of culture on customers' satisfaction of the overall service assessment of RO

\section{Methodology}

The research strategy for this paper nested on the quantitative research method. A survey of customers within the bank's premises provided sample data for this study. The survey instrument used addressed the basic research questions and had previously been validated in other studies (Athanasopoulou, 2009; Hofstede, 1984; Sivadas, et al, 2008; Wan, et al, 2009; Wan, et al, 2012). The arrangements of the survey questions addressed possible biases, avoided priming and the "survey ordering effects" (Bishop, Oldendick \& Tuchfarber, 1985; Phil, 2011). The entire active customer base of the bank's branches covered was 2,765,678. This research administered 1400 customers, noting that a sample size of 500 suffices to achieve a margin of error corridor of $\pm 5 \%$ (Hair, et al, 2013; Leedy \& Ormrod, 2013).

The need for data integrity guided the data collection and preparation processes (Gordon, Lin, Cave \& Dandrea, 2015). The overall response rate was $86 \%$ while the valid response rate stood at $75.86 \%$. This translated to 1062 valid responses that were encoded and subsequently treated for missing data consistent with Dong's and Peng's (2013) position that the proportion of missing data directly influences the quality of research result (Schlomar, Bauman \& Card, 2010). An insignificant 1.3\% missing data was noted compared to the recommended 5\%-20\% threshold (Saunders, Morrow-Howell, Spitznagel, Dori, Proctor \& Pescarino, 2006). This paper adopted the "between subjects mean imputation technique of replacing missing data to obtain a complete data set for the 1062 variable cases. This research adopted several analytical tools described under the data analysis section. 


\section{Data Analysis}

Averages were used to compare customers' perceptions of satisfaction of the overall service assessment of the bank with the RO. The structural equation modelling (SEM) was applied to determine the structural relationships amongst the variables. SEM process was operationalized through the reliability, validity and path analysis structures. First, the item-total correlation (ITC) on the two independent variables tested for construct reliability (Appendices 1 and 2). One indicator showed weak ITC (Talk) for the relationship quality factor while all but three indicators (collegiate attitude, pride in family, and natural competition) showed weak ITC for the culture factor. The resulting Cronbach Alphas remained strong for both factors at.805 and 795, indicating strong reliability of the constructs (Kourkounasiou \& Skordilis, 2014; Mackenzie, Podsakoff \& Podsakoff, 2011).

This research operationalized the factorization of the indicators that showed strong construct reliability (asterisked in Appendices 1 and 2) to produce meaningful regrouped factorable variables with common factors according to their shared variances (Field, 2005; Hair, et al, 2010; Martin, Pearson, Cai, Elmer, Horgan \& Lindley,
2003). Principal component analysis performed on the qualifying indicators with reliability (Appendices 1 and 2), provided validity for four and two indicators respectively for RQ and the culture factors. SEM was then performed on the indicators that showed construct reliability and validity.

\section{Result of the Analysis and Discussion}

\subsection{Averages (Addressing Hypothesis 1)}

Figure 2 and Appendix 6 showed that customers were on the average better satisfied with the RO than they were with the engrained services provided by the bank's platform. Fifteen percent $(55 \%$ - 40\%) more customers expressed satisfaction with RO than with the bank and ten percent $(16 \%-26 \%)$ less expressed dissatisfaction with RO than with the bank. Further, five percent less customers stayed neutral in evaluating the RO compared to overall bank $(28 \%-33 \%)$. The average perception score of satisfaction by customers concerning the overall service assessment of the RO and the bank ranked at 3.4 and 2.8 on a Likert scale of 5 with a modal rank of 4 and 3 respectively (figures 3 and 4)

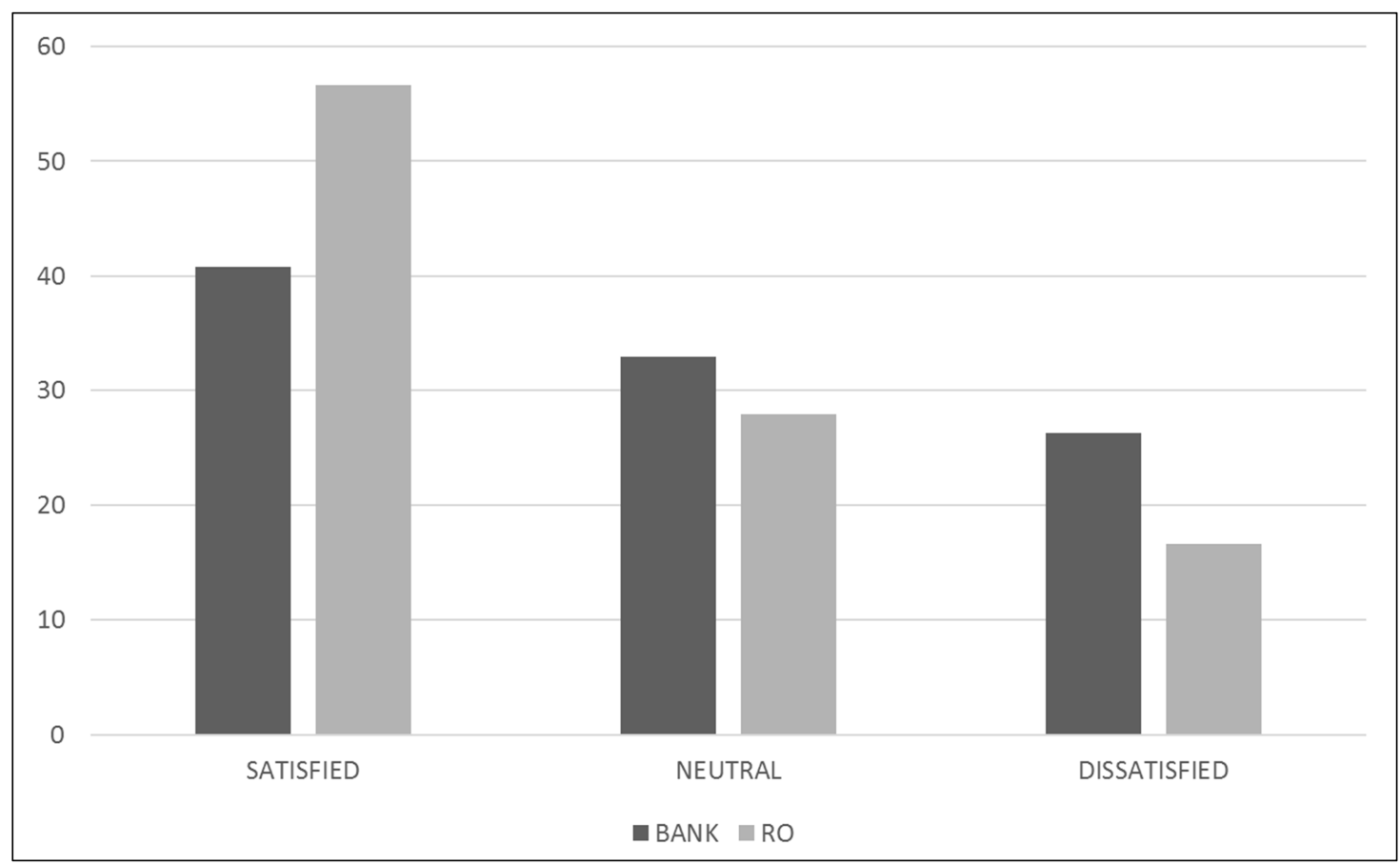

Figure 2. Customers 'satisfaction perceptions with the bank and RO.

The results support the first thesis of this research that the level of customers' satisfaction of the overall service assessment is higher towards the RO than towards the bank. The result is supported by Wan, et al (2012) that posited that RQ could mediate the effects of poor service quality. This result also has some nomological appeal because in reality customers actually remain with a bank even when the quality of the core service provided is somewhat compromised for as long as they are enthused by the RO. The strength of the bond between the RO and the customers is likely to cause the customers to overlook some failures in core service quality. 
7.2. Structural Equation Modeling (Addressing Hypotheses 2-7)

7.2.1. Post Mediation Model for the Satisfaction with RO $(\alpha)$

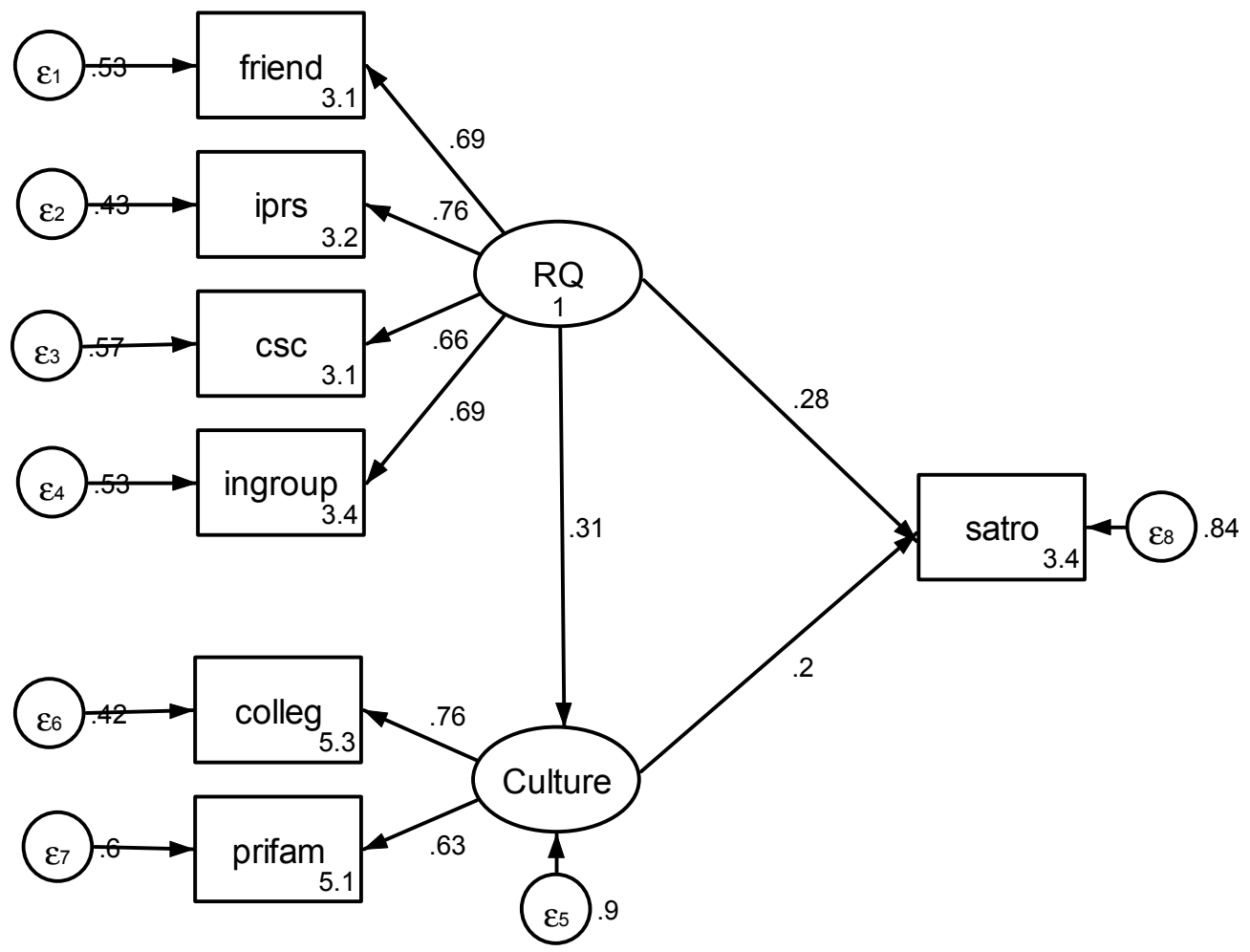

Figure 3. Post Mediation $\alpha$ Model.

\subsubsection{Post Mediation Model for the Satisfaction with Bank's Services $(\lambda)$}

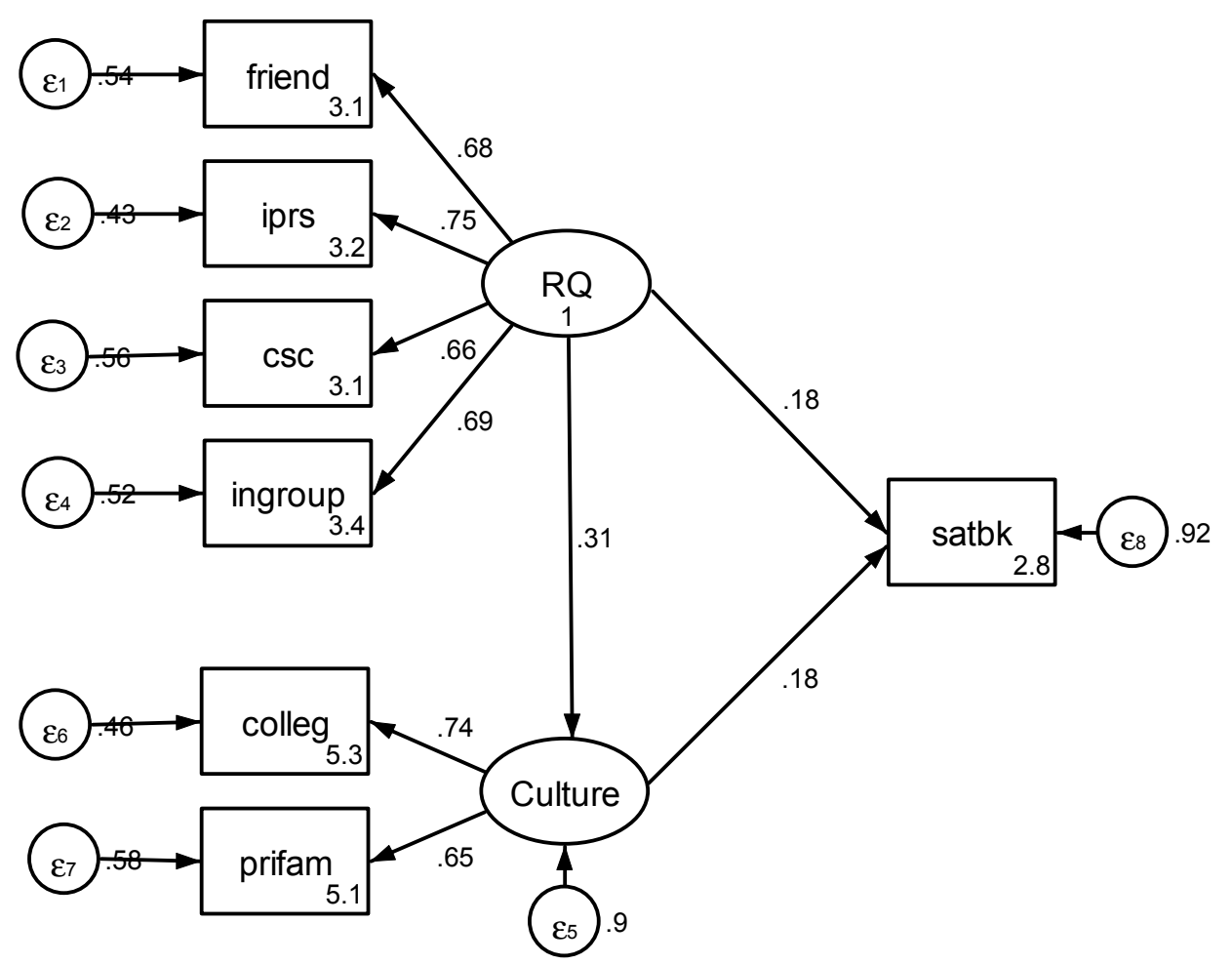

Figure 4. Post Mediation A Model. 


\subsection{Model's Goodness of Fit}

Figures 3 and 4 show both the averages and structural relationships between the variables in the models. However, the relationships are considered useful only when model validity has been proven. Model validity measured by the goodness of fit provides evidence of the consistency of the data with the underlying theoretical framework. Model fit thus, tests the reproducibility of a model to make good predictions that generates structurally similar data in the future (Hair, et al, 2013). Table 1 shows a set of complementary model GOF tests.

Table 1. Goodness of fit indices.

\begin{tabular}{lllllll}
\hline \multirow{2}{*}{ Fitness indices } & \multicolumn{2}{l}{ Acceptable Limits* } & RO Indices & & \multicolumn{2}{c}{ Bank Indices } \\
\cline { 2 - 7 } & Lenient & Stringent & Pre $\boldsymbol{\alpha}$ & Post $\boldsymbol{\alpha}$ & Pre $\boldsymbol{\lambda}$ & Post $\boldsymbol{\lambda}$ \\
\hline Chi Square $\left(\chi^{2}\right)$ & Low $\chi^{2}$ & & 150.8 & 95.28 & 148.95 & 93.51 \\
Degree of Freedom (DF) & $(\mathrm{K})(\mathrm{K}+1) / 2$ & 13 & 12 & 13 & 12 \\
P-Value & Insignificant. $(\mathrm{P}>.05)$ & .0000 & .0000 & .0000 & .0000 \\
Relative $\chi^{2}\left(\chi^{2} / \mathrm{DF}\right)$ & $\leq 5.0$ & $\leq 2.0$ & 11.6 & 7.94 & 11.45 & 7.79 \\
RMSEA (Root mean Square Error of Approx.) & $\leq .07$ & $\leq .03$ & .100 & .081 & .099 & .080 \\
RMSEA Lower bound & - & - & .086 & .066 & .085 & .065 \\
RMSEA Upper bound & - & - & .115 & .096 & .114 & .095 \\
Comparative Fit Index (CFI) & $\geq .90$ & $\geq .96$ & .920 & .952 & .918 & .951 \\
Tucker-Lewis Coëfficiënt/NFI & $\geq .90$ & $\geq 96$ & .871 & .915 & .868 & .914 \\
Standardized Root Mean Residuals (SRMR) & $\leq .09$ & $\leq .08$ & .080 & .031 & .079 & .031 \\
Model Coefficient of Determination (CD) & $\geq .70$ & $\geq .90$ & .934 & .803 & .930 \\
\hline
\end{tabular}

Different indices typically reflect different aspects of a model fit (Hooper, Coughlan \& Mullen, 2008; Lu \& Bentler, 2009). However, Hu and Bentler (1999) as cited by Hooper, et al, (2008) suggested the Two-Index fit combination Strategy of NNFI (TLI) and SRMT, RMSEA and SRMR, or CFI and SRMR (Recommended limits in Table 1). The idea is that the fit indices reflect a mix of absolute and relative fit indices, which this model has achieved but more importantly, the results reflect the underlying theory. Table 1 showed that the post mediation model produced a superior fit than the pre mediation model across the several indices including the large relative Chi square that improved upon mediation. Consequently, this research adopted the post mediation model as better fit for the data and the underlying theoretical constructs. The research results addressing hypotheses 2 through to 7 are captured in Table 2.

\subsection{Summary Results of the Research}

The coefficient estimate of the paths in figures 3 and 4 and
Appendices 7 an 8 (Standardized parameter estimates) showed the structural relationships between the independent variable constructs and the dependent variables in the two models $(\alpha$ and $\lambda$ ). As indicated in Table $1, \mathrm{P}<.05$, implying that the results are statistically significant and provide dependable results. The structural relationships as espoused in Figures 3 and 4, juxtaposed with Appendices 7 and 8, provide evidence of partial mediation for both the satisfaction with RO and satisfaction with bank models. In each of the cases, the pre mediation coefficients linking RQ to the dependent constructs were larger than the post mediation indicating the shared influence of RQ and culture over the dependent variables post mediation (See the coefficient estimates in Figures $3 \& 4$ and Appendices $7 \& 8$ ). On the basis of the analysis in the foregoing sections, the research results are summarized below, stating the acceptance or otherwise of the hypotheses set out in section 4. of this paper. (The pre mediation parameters can be viewed in Appendices 7 and 8)

Table 2. Results of the Research (Post mediation parameters).

\begin{tabular}{|c|c|c|c|c|c|c|c|}
\hline \multirow{3}{*}{ HYP } & \multirow{3}{*}{ Relationships between the hypothesized variables in the model } & \multicolumn{6}{|c|}{ Standardized effect $(\beta)$ and $P$ value } \\
\hline & & \multicolumn{3}{|c|}{ Bank } & \multicolumn{3}{|c|}{ RO } \\
\hline & & $\boldsymbol{\beta}$ & $\mathbf{P}$ & HS & $\boldsymbol{\beta}$ & $\mathbf{P}$ & HS \\
\hline $\mathrm{H} 2$ & \multirow{2}{*}{ RQ is positively associated with customer's satisfaction of overall service assessment of the } & .18 & $<.05$ & Y & - & - & - \\
\hline H5 & & - & - & - & .28 & $<.05$ & $\mathrm{Y}$ \\
\hline H3 & \multirow{2}{*}{$\begin{array}{l}\text { Culture is positively associated with customers' satisfaction of overall service assessment of } \\
\text { the }\end{array}$} & .18 & $<.05$ & $\mathrm{Y}$ & - & - & - \\
\hline H6 & & - & - & - & .20 & $<.05$ & $\mathrm{Y}$ \\
\hline H4 & \multirow{2}{*}{$\begin{array}{l}\text { RQ mediates the effect of Culture on customer satisfaction of the overall service assessment } \\
\text { of the }\end{array}$} & .31 & $<.05$ & Y & - & - & - \\
\hline H7 & & - & - & - & .31 & $<.05$ & $\mathrm{Y}$ \\
\hline
\end{tabular}

$\beta=$ Standardized Coefficient, Statistical significance is set at $\mathrm{P}<.05, \mathrm{HS}=$ Hypothesis supported, $\mathrm{Y}=$ Yes. 


\section{Delimitations of the Study}

This study used primary data obtained from strictly retail banking outlets in a particular region of a bank in Nigeria. The delimitation of the research, while intentional for practical reasons, may constrain generalization of the results to other banking segments like corporate, personal and institutional customers.

\section{Limitations of the Study}

This study used data from a particular bank and to that extent the outcome may not be generalizable within Nigeria and other climes having different culture. This is the usual drawback associated with case study research. However, given the large sample size and the archetypical structure and operational dynamics of banks in the country, the results may strike the right chord with management of banks. Future studies may focus on cross sectional study of banks to gain better insights into customers' attitudes and perceptions towards banks and the relationship officers that work for the banks

\section{Conclusion}

Table 2 demonstrated that hypotheses 2 through to 7 were supported by this research. More revealing however, is a form of triangulation of the first hypothesis. The research results posting stronger positive coefficient between RQ and the RO construct compared against RQ coefficient to the satisfaction construct with the overall bank's services, is a clear indication of the stronger bond between the RO and the customers than with the customers to the bank as an institution. This implies that the customers place premium importance on the quality relationship nurtured with them by the RO over and above the importance they place on the relationship with the bank as an institution. This fact drives customers' ability to forgive (Su, 2014; Yagil \& Luria, 2015) and overlook some shoddiness or failure in core service quality provided by the bank. Avery, Fournier and Wittenbraker, (2014) provided research evidence that customers' grudges and frustrations following transgression could potentially strengthen relationship quality through efficient relationship management mechanisms. Finally, while a positive relationship had been established across the hypotheses raised for this study, covering the customers' overall service assessment of the bank and the RO, the consistent theme is that of a stronger relationship between the customers and RO across the entire study. The customers believed that they received superior satisfaction from the RO than from the bank. They held that the relationship between RQ and the RO is stronger than RQ with the entire bank, implying that they ignored the contributory platform upon which the RO stood to perform their relationship duties. This irony holds significance for banks to focus on their service platform delivery mix in structuring their service architecture.

\section{Recommendations}

On the strength of the consistent superior satisfaction perceptions recorded for customers concerning the RO against the entire bank's platform, It is the recommendation of this paper that banks need to establish a robust migration strategy in their "platform and channel" mix. The market and social forces continue to pile pressure on banks for digital substitution of the service platform by increasingly replacing RO with other tools and digital substitutes. In response to these market and social pressures, banks should understand the structures and digital maturity of their markets before they bandwagon into a full digital migration that may or may not serve their unique markets well. RO continues to be relevant in some markets and may remain so in the foreseeable future. There is also the need to understand customers' key expectations from the RO as a means of reimaging and restructuring service architecture to deliver services that exceeds customers' expectations. Therefore, in the final analysis, whether a bank is high or low on digital, may not be the critical point. Digital is a means. The specific requirements of customers that trigger superior fidelity to the RO compared to the entire bank's service platform must be addressed in the long run.

\section{Appendix}

Appendix 1: Item-Total Correlation Matrix of relationship Quality Indicators

Table 3. Item-Total Correlation Matrix of relationship Quality Indicators.

\begin{tabular}{|c|c|c|c|c|c|c|}
\hline \multirow{2}{*}{$\mathbf{S} / \mathbf{N}$} & \multirow{2}{*}{ Latent Variables } & \multirow{2}{*}{ Service Indicators } & \multicolumn{2}{|l|}{ Sub Constructs } & \multicolumn{2}{|c|}{ Main Construct } \\
\hline & & & Correlation & Cronbach $\alpha$ & Correlation & Cronbach $\alpha$ \\
\hline 1 & MD & Talk & .372 & & .429 & \multirow{6}{*}{.805} \\
\hline \multirow[t]{3}{*}{2} & MD & Chat & .372 & & $.550^{*}$ & \\
\hline & Friend & Friend & .572 & .541 & $.617 *$ & \\
\hline & Friend & IPRS & .572 & $\begin{array}{r}.727 \\
706\end{array}$ & $.645^{*}$ & \\
\hline \multirow{2}{*}{3} & Soc. ID & CSC. & .546 & .706 & $.580 *$ & \\
\hline & Soc. ID & In group & .546 & & $.565 *$ & \\
\hline
\end{tabular}




\section{Appendix 2: Item-Total Correlation Matrix of Culture Indicators}

Table 4. Item-Total Correlation Matrix of Culture Indicators.

\begin{tabular}{llllll}
\hline \multirow{2}{*}{ S/N } & Latent Variables & Service Indicators & Sub Construct & & Main Construct \\
\cline { 4 - 6 } & & Correlation & Cronbach $\boldsymbol{\alpha}$ & Correlation & Cronbach $\boldsymbol{\alpha}$ \\
\hline 1 & HC & Rel. happy & 365 & .642 & .384 \\
2 & HC & Collegiate att. & .481 & .448 & $.514^{*}$ \\
3 & HC & Support & .403 & .560 & .495 \\
& HC & Cooperation & .453 & & .481 \\
& VC & Family values & .215 & .228 \\
& VC & Sac family & .340 & .386 & $.547^{*}$ \\
& VC & Pride family & .206 & .47 & .795 \\
& VC & Respect family & .265 & .485 & .302 \\
4 & HI & Uniqueness & .420 & & .494 \\
& HI & Loner & .307 & & .468 \\
& HI & Unique Ind. & .403 & $.520^{*}$ \\
& VI & Competitive & .417 & .395 \\
\hline
\end{tabular}

Appendix 3: Component Matrix for Relationship Quality Construct

Table 5. Component Matrix for Relationship Quality Construct.

\begin{tabular}{llcl}
\hline & Component 1 & Communalities extracted \\
\hline Mutual disclosure-chat & - & .468 & .608 \\
Friendship-friend & .780 & .639 & .539 \\
Friendship-interposal relationship & .799 & .734 & .566 \\
Social identity-common shared values & .752 & & \\
Social identity-in grouper & & & \\
\hline
\end{tabular}

Appendix 4: Component Matrix for Culture Construct

Table 6. Component Matrix for Culture Construct.

\begin{tabular}{llc}
\hline & Component 1 & Communalities extracted \\
\hline HC-collegiate attitude & .768 & .590 \\
VC-pride in family & .834 & .695 \\
\hline
\end{tabular}

\section{Appendix 5: Dependent Constructs (Endogenous Variables)}

Table 7. Dependent Constructs (Endogenous Variables).

\begin{tabular}{lll}
\hline Measured construct/variable & Variables (measured) unidimensional & Codes used in SEM \\
\hline Satisfaction with bank services & Ditto & satis_bk $(\lambda)$ \\
Satisfaction with relationship off & Ditto & satis_ro $(\alpha)$ \\
\hline
\end{tabular}

\section{Appendix 6: Customers Relative Assessment of Bank and RO}

Table 8. Customers Relative Assessment of Bank and RO.

\begin{tabular}{llll}
\hline S/N & Assessment Grid & Percent of customers who assessed the bank's services & Percent of customers who assessed the RO's effectiveness \\
1 & Satisfied & 40.8 & 56.6 \\
2 & Neutral & 32.9 & 27.9 \\
3 & Dissatisfied & 26.3 & 16.5 \\
& Total & 100.0 & 100.0 \\
\hline
\end{tabular}


Appendix 7: Pre Mediation Model of Satisfaction with RO

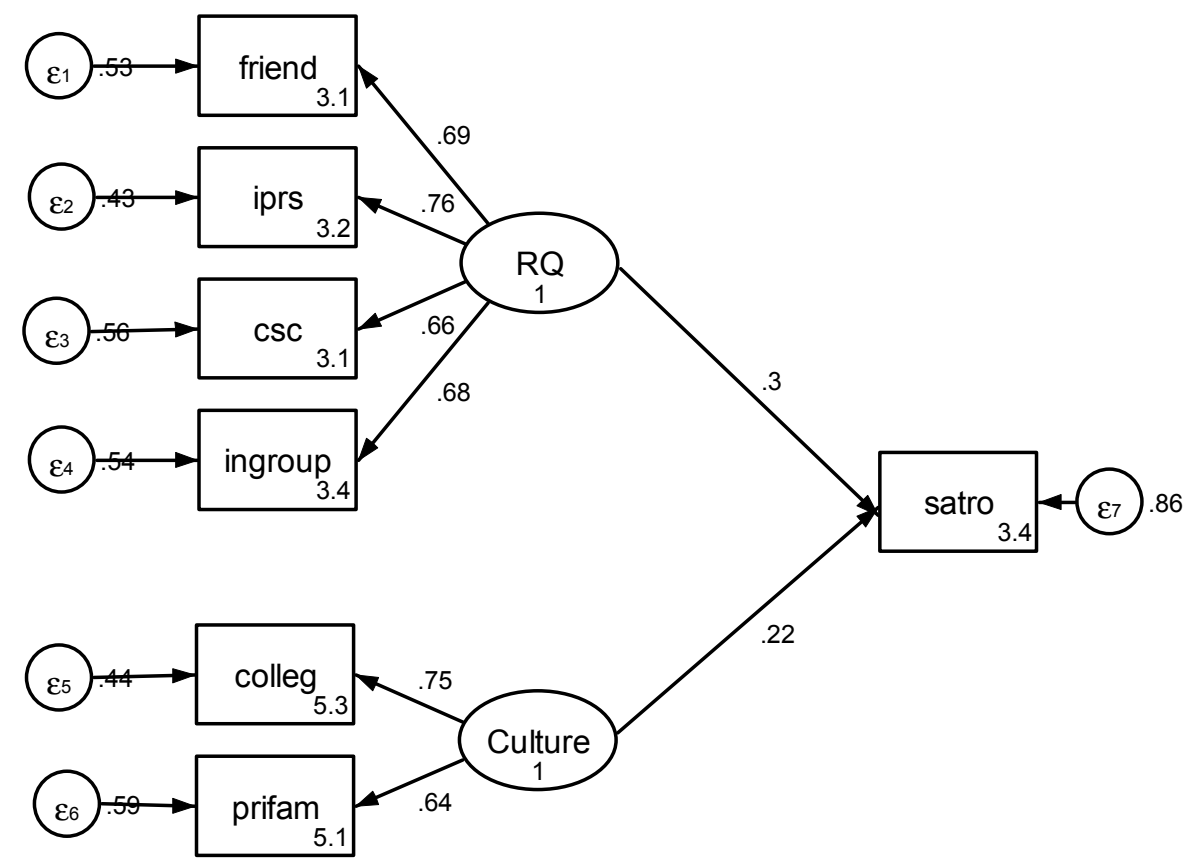

Figure 5. Pre Mediation Model of Satisfaction with RO.

Appendix 8: Pre Mediation Model of Satisfaction with Bank

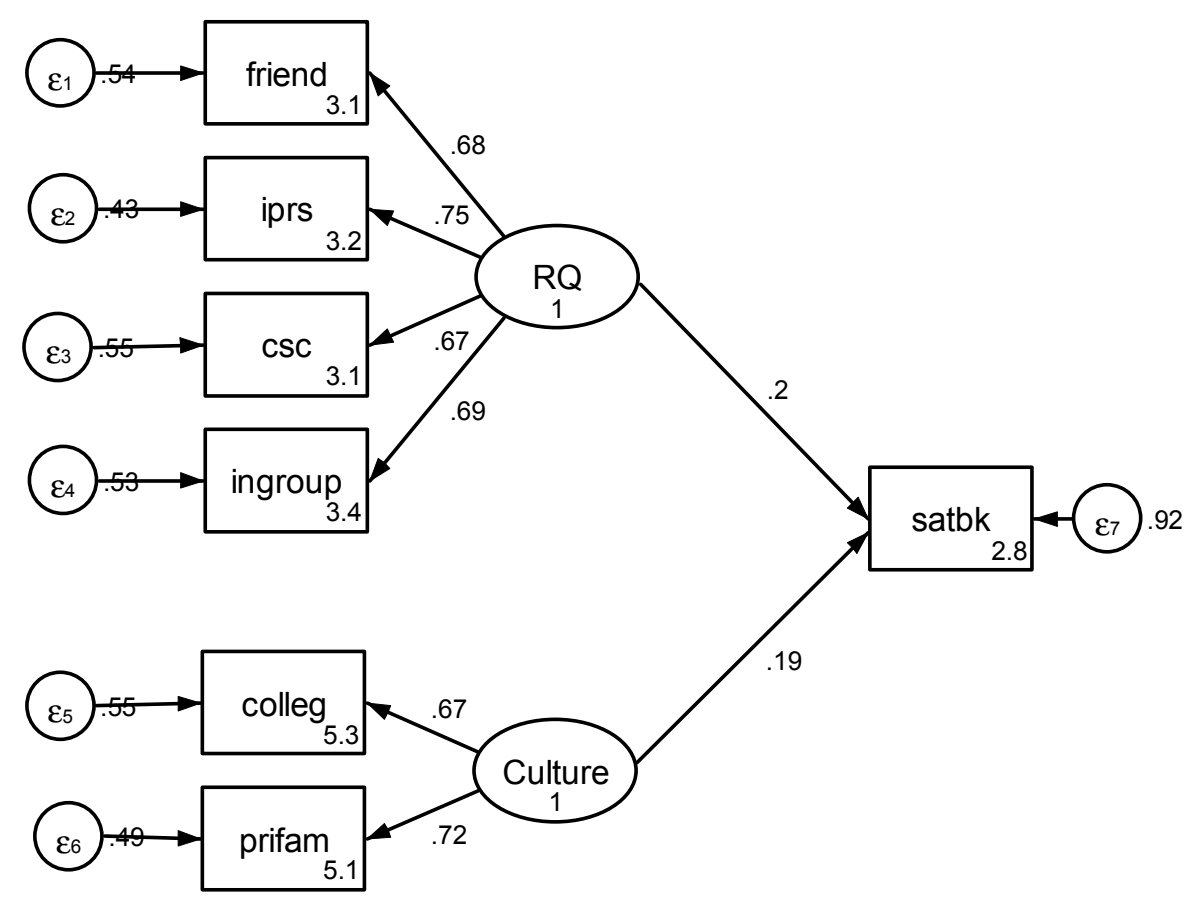

Figure 6. Pre Mediation Model of Satisfaction with Bank.

\section{References}

[1] Ajzen, I. (2002). Perceived Behavioral Control, Self-Efficacy, Locus of Control, and the Theory of Planned Behavior. Journal of Applied Social Psychology, 32 (4), 665-683.

[2] Ajagbawa, H. O. (2016). Behaviors of rural and urban customers towards retail banking services. (Ph.D. Dissertation). Retrieved from www.academia.edu/.../Behaviors_of_rural_and_urban_custom ers_towards_retail_banki...

[3] Athanasopoulou, P. (2009). "Relationship quality: a critical literature review and research agenda", European Journal of Marketing, 43 (5/6), 583-610. 
[4] Avery, J., Fournier, S., \& Wittenbraker, J. (2014). Unlock the mysteries of your customer relationships. Harvard Business Review, 92 (7/8), 72-81.

[5] Benamour, Y., \& Prim-Allaz, I. (2010). Transactional versus Relational Customer Orientation: Developing a Segmentation Tool in the French Banking Industry An exploratory study. 7th Relationship Marketing Colloquium: Delivering Value Out Of Bounds, Nov 1999, Glasgow, UK.

[6] Bishop, G. F., Oldendick, R. W., \& Tuchfarber, A. J. (1985). The Importance of Replicating a Failure to Replicate: Order Effects on Abortion Items. Public Opinion Quarterly, 49 (1), 105-114.

[7] Bobbio, A., Sarrica, M. (2009). Horizontal and vertical individualism and collectivism: an Italian adaptation of singelis et al. scale and its relations with conflict management and leadership styles. TPM 16 (4), 209-226.

[8] Collett, J. L. (2011). (Re) Integrating Simmel in Contemporary Social Exchange: The Effect of Nonpartisans on Relational Outcomes. Social Forces, 90 (2), 617-637.

[9] Crosby, A., Evans, K. R., \& Cowles, D. (1990). Relationship quality in services selling: An Interpersonal Influence Perspective. Journal of Marketing, 54 (3), 68-81.

[10] Dimitriadis, S., Stevens, E. (2008)."Integrated customer relationship management for service activities: An internal/external gap model", Managing Service Quality: An International Journal, 18 (5), 496-511.

[11] Dong, Y. \& Peng, C. J. (2013). Principled missing data methods for researchers. Springer Plus 2013, 2:222. Retrieved from http://www.springerplus.com/content/2/1/222

[12] Field, A. P. (2005) Discovering statistics using SPSS (2nd Edition) chapter 5. Retrieved from http://www.statisticshell.com/docs/reliability.pdf

[13] Gordon, C., Lin, J., Cave, R., \& Dandrea, R. (2015). The Question of Data Integrity in Article-Level Metrics. DOI: 10.1371/journal.pbio.1002161

[14] Goffin, K. (1998) Customer support distribution channels: five exploratory case studies. Retrieved from https://core.ac.uk/download/pdf/139922.pdf.

[15] Groysberg, B., Ashish, N., and Nitin, N (May 2004). The Risky Business of Hiring Stars. Retrieved from https://hbr.org/2004/05/the-risky-business-of-hiring-stars.

[16] Hair, J. F., Black, W. C., Barry, J. B., \& Rolph, E. A. (2013). Multivariate Data Analysis. Seventh Edition. Pearson ISBN $13:: 978-1-292-02190-4$.

[17] Herold, D., \& Fedor, D. (2008). Change- The way to lead change. ISBN.

[18] Hofstede, G. (2011). Dimensionalizing Cultures: The Hofstede Model in Context. Online Readings in Psychology and Culture, 2 (1). http://dx.doi.org/10.9707/2307-0919.1014.

[19] Hooper, D., Coughlan, J., and Mullen, M. R. (2008). Structural Equation Modelling: Guidelines for Determining Model Fit. Electronic Journal of Business Research Methods, $6(1), 53-60$.

[20] Huang, Ching-Hsu. (2013). Mediating effect of relationship quality on customer loyalty in franchising beverage store. African Journal of Business Management Vol. 7 (35), 33813393. DOI: 10.5897/AJBM11.933.
[21] Hughes, J. P. \& Mester, L. J. (2008). Efficiency in Banking: Theory, Practice, and Evidence. Retrieved from http://fic.wharton.upenn.edu/fic/papers/08/0825.pdf.

[22] Keen, M., Kaushik, R., Bhogal, K. S., Agbara, A., Simmons, S., DuLaney, R., Dube, S., and Allison, A. (2009). Red Paper. IBM Banking industry framework. Retrieved from http://www.redbooks.ibm.com/redpapers/pdfs/redp4467.pdf.

[23] Kearney, A. T. (2009). The five forces shaping the banking industry: Preparing for the Economic recovery. Retrieved from https://www.atkearney.com/documents/10192/296636/Five_For ces_Shaping_Banking.pdf/9a0bcd47-8572-4dba-9aa1$8 \mathrm{ec} 204 \mathrm{ffbeac}$

[24] Kittemann, F., Göttl, M., Gabriel, A., Menrad, K. (2008). Comparison of customer satisfaction in different types of distribution channels of horticultural products in Austria and Bavaria Paper prepared for presentation at the First Symposium on Horticulture in Europe (SHE) 17th to 20th February 2008 at Vienna/Austria held under the aegis of ALVA, APH, BNL-SHS, DGG, GSHS, IOH, INRA, NJF, PSHS, SECH, SOI and the International Society for Horticultural Science.

[25] Kourkounasiou, M. A., \& Skordilis, E. K. (2014). Validity and reliability evidence of the TOCA-C in a sample of Greek students. Psychological Reports, 115 (3), 766-783.

[26] Leedy, P.D., \& Omrod, L. E. (2013). Practical research: Planning and design. $\left(10^{\text {th }}\right.$ Ed.) New Jersey, USA. Pearson. ISBN:13-978-0-13-269324-0.

[27] Levine, R. (2005) Finance and Growth: Theory and Evidence. NBER Working Paper No. 10766. Issued in September 2004. NBER Program(s): CF EFG IFM. Retrieved from http://www.nber.org/papers/w10766.

[28] Lilien, G. L., and Grewal, R. (Ed) (2012). Handbook on Business to Business Marketing ISBN: 9781849801423. Retrieved from https://books.google.com.ng/books?id=nSiEQYBan18C\&prints $\mathrm{ec}=$ frontcover\&source $=\mathrm{gbs} \_\mathrm{vpt} \_$buy $\# \mathrm{v}=$ onepage $\& \mathrm{q} \& \mathrm{f}=$ false.

[29] Lu, L., Bentler, P. M (2009). Cutoff criteria for fit indexes in covariance structure analysis: Conventional criteria versus new alternatives. Structural Equation Modeling: $A$ Multidisciplinary Journal, 6 (1). DOI: 10.1080/10705519909540118.

[30] Martin, A. R., Pearson, J. D., Cai, B., Elmer, M. Horgan, K., and Lindley, C. (2003). Assessing the impact of chemotherapy-induced nausea and vomiting on patients' daily lives: a modified. Supportive care in cancer, 11 (8), 522-527.

[31] McAuley, J., Duberley, J., and Johnson, P. (2007). Organization Theory Challenges and Pers--pectives Pearson Education Limited, Edinburgh Gate, UK. ISBN-13: 978-0273-68774-0.

[32] Palmatier, R. W., Dant, R. P., Grewal, D., \& Evans, K. R. (2006). Factors Influencing the Effectiveness of Relationship Marketing: A Meta-Analysis. Journal of Marketing 70 (4), $136-153$.

[33] Phil, G. (March 2, 2011) Question Order Matters. Survey Science. Survey Monkey Blog. Retrieved from https://www.surveymonkey.com/blog/2011/03/02/questionorder-matters/. 
[34] Podsakoff, P. M., MacKenzie, S. B., Lee, J. Y., \& Podsakoff, N. P. (2003). Common method biases in behavioral research: A critical review of the literature and recommended remedies. Journal of Applied Psychology, 88 (5), 879-903. doi: 10.1037/0021-9010.88.5.879.

[35] Samaha, S. A., Beck, J. T., \& Palmatier, R. W. (2014). The Role of Culture in International Relationship Marketing. Journal of Marketing, 78 (September 2014), 78-98.

[36] Saunders, J. A., Morrow-Howell, N., Spitznagel, E., Dori, P., Proctor, E. K., \& Pescarino, R (2006). Imputing Missing Data: A Comparison of Methods for Social Work Researchers. Social work research, 30 (i), 19-31.

[37] Schlomer, G. L., Bauman, S., \& Card, N. A. (2010) Best Practices for Missing Data Management in Counseling Psychology. Journal of Counseling, 57 (1), 1-10.

[38] Singh, P. (2014). Branch banking to virtual banking utilization of direct banking channel in indian banking sector. European Journal of Accounting Auditing and Finance Research Vol.2, No.8, pp.1-8, October 2014.

[39] Sivadas, E., Bruvold, N. T., \& Nelson, M. R. (2008). A reduced version of the horizontal and vertical individualism and collectivism scale: A four-country assessment. Journal of Business Research 61 (2008) 201-210. doi: 10.1016/j.jbusres.2007.06.016.

[40] Spain, E., Groysberg, B (2016). Managing People: Making Exit Interviews Count. Harvard Business Review. April 2016 Issue p.88-95.
[41] Steel, P., \& Taras, V. (2010). Culture as a consequence: A multi-level multivariate meta-analysis of the effects of individual and country characteristics on work-related cultural values. Journal of International Management 16 (3) 211-233.

[42] Su, L. (2014). Understanding psychological contract breach in the customer-firm Relationship (Ph.D. Dissertation) Iowa state University. Retrieved from lib.dr.iastate.edu/cgi/viewcontent.cgi? article $=4832$ \& context $=$ etd.

[43] Wan, W. W. N., Luk, C., Fam, F., Wu, P., \& Chow, C. W. C. (2012) Interpersonal relationship, Service Quality, Seller Expertise: How Important Are They to Adolescent Consumers? Psychology and Marketing, 29 (5): 365-377. DOI: 10.1002/mar.20527.

[44] Wan, W. W. N., Luk, C., Yau, O. H. M., Tse, A. C. B., Sin, L. Y. M., Kwong, K. K., \& Chow, R. P. M. (2009). Do Traditional Chinese Cultural Values Nourish a Market for Pirated CDs? Journal of Business Ethics, 88:185-196. DOI 10.1007/s10551-008-9821-1.

[45] Wernerfelt, B. (2013). Small forces and large firms: Foundations of the RBV Small forces and large firms: Foundations of the RBV. Strategic Management Journal, 34 (6), 635-643.

[46] Yagil, D., \& Luria, G. (2015). Customer forgiveness of unsatisfactory services: manifestation and antecedents. Doi: 10.1007/s11628-015-0282-1. 